\title{
Synthesis of substituted isoindolo[2,1-a]quinoxalin-6-yl-amino and 6-imino-5-yl thiourea derivatives
}

\author{
Barbara Parrino, Cristina Ciancimino, Chandrakant Sarwade, Virginia Spanò, Alessandra \\ Montalbano, Paola Barraja, Girolamo Cirrincione, Patrizia Diana, and Anna Carbone* \\ Dipartimento di Scienze e Tecnologie Biologiche Chimiche e Farmaceutiche, Università degli Studi \\ di Palermo, Via Archirafi 32, 90123 Palermo, Italy \\ E-mail: anna.carbone@unipa.it
}

DOI: $\underline{\text { http://dx.doi.org/10.3998/ark.5550190.p008.582 }}$

\begin{abstract}
A series of substituted 1-(5-bromopyridin-2-yl)-3-[2-(isoindolo[2,1-a]quinoxalin-6ylamino)ethyl]thiourea and 1-(5-bromopyridin-2-yl)-3-[2-(6-iminoisoindolo[2,1-a]quinoxalin$5(6 H)$-yl)ethyl]thiourea derivatives were prepared in good yields $(63-85 \%)$ by reaction between the corresponding amino compounds with 5-bromo-2-isothiocyanatopyridine. All thiourea derivatives, tested for inhibition of HIV-1 RT, showed no significant antiviral activity.
\end{abstract}

Keywords: AIDS, NNRTIs, isoindolo-quinoxalines, quinoxalinylethylpyridylthioureas, antiviral activity

\section{Introduction}

Human immunodeficiency virus (HIV) is a retrovirus responsible for transmission and development of the acquired immune deficiency syndrome (AIDS). It is characterized by the presence of a viral reverse transcriptase (RT) that is able to synthesize DNA from the viral RNA genoma. Due to its important role in the viral life cycle, this enzyme is considered an excellent target in the chemotherapy against AIDS. In the current treatment strategy, called highly active antiretroviral therapy (HAART), HIV-1 RT inhibitors are used in combination with HIV-1 protease inhibitors. $^{1-3}$

There are two classes of HIV-1 RT inhibitors: nucleoside analogues (NRTIs), for example AZT, ddI, ddC, d4T and non-nucleoside analogues (NNRTIs), for example nevirapine, efavirenz, delarvidine. NRTIs are competitive inhibitors that act at the catalytic site of the enzyme by interrupting DNA synthesis. ${ }^{4}$ NNRTIs are non-competitive inhibitors, structurally diverse, that bind to a hydrophobic pocket located approximately $10 \AA$ away from the catalytic 
site. Their binding leads to a distorsion of the catalytic pocket preventing the enzyme to carry out its normal functions. ${ }^{5,6}$

Most NNRTIs are highly specific against HIV-1 RT and have a low toxicity for the human cells but show a reduced efficacy against mutated variants of RT. ${ }^{7,8}$

For this reason in the last years many efforts have been done to find new NNRTIs able to inhibit both wild-type and mutants HIV-1 RT that are resistant to the common antiretroviral drugs. ${ }^{9,10}$

The quinoxaline ring and structurally related quinoxalinone constitute the skeleton of many compounds showing a variety of biological activities. ${ }^{11}$ Some quinoxaline derivatives (for example S-2720, ${ }^{12}$ HBY097 ${ }^{13}$ and GW420867X ${ }^{14}$ ) have been reported as excellent NNRTIs and in particular HBY 097 and GW420867X were also selected for clinical trials. They were highly potent inhibitors of HIV-1 replication in different human cell lines showing $\mathrm{IC}_{50}$ values in the low nanomolar range. The compounds were also active against various HIV-1 subtypes and mutant reverse transcriptases. Compounds with a heteroarylsulfonylquinoxaline structure were also reported for their properties to inhibit the RT with $\mathrm{IC}_{50}$ at submicromolar range (Figure 1). ${ }^{15}$<smiles>C=C(C)OC(=O)N1c2cc(Cl)ccc2NC(=S)C1(C)C</smiles>

S-2720<smiles>CC[C@H]1C(=O)Nc2ccc(F)cc2N1C(=O)OC(C)C</smiles>

GW420867X<smiles>COc1ccc2c(c1)N(C(=O)OC(C)C)[C@H](CSC)C(=S)N2</smiles>

HBY097

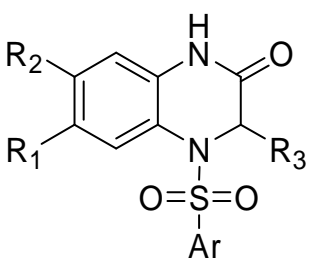

$\mathrm{N}^{4}$-(hetero)arylsulfonylquinoxalinones

Figure 1. NNRTIs having a quinoxaline skeleton.

Quinoxalinylethylpyridylthioureas (QXPTs) of type 1 and 2 (Figure 2) represent another class of NNRTIs; many compounds showed a potent activity against both HIV-1 wild-type RT and various HIV-1 mutants HIV-1 RT. ${ }^{16}$ Considering the good experience reached in the course of our researches on polycyclic nitrogen systems, bearing pyrrole, ${ }^{17-24}$ indole, ${ }^{25-35}$ isoindole ${ }^{36-38}$ and indazole ${ }^{39}$ moieties, we have decided to synthesize the QXPT analogues of type $\mathbf{3}$ and $\mathbf{4}$ bearing an isoindole moiety instead of the five-membered heterocyclic ring. Moreover the replacement 
of the oxygen atom with a nitrogen atom could have increased the pharmacokinetic profile (Figure 2).
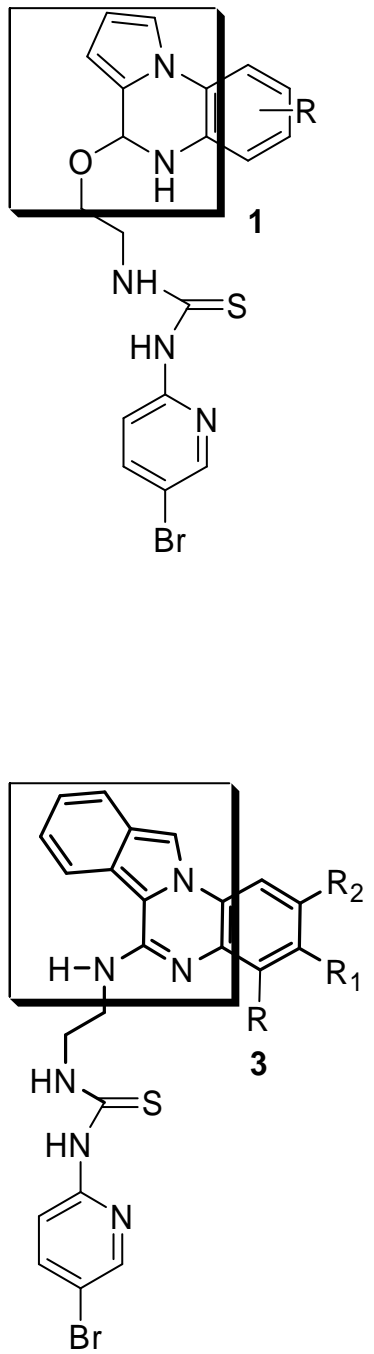
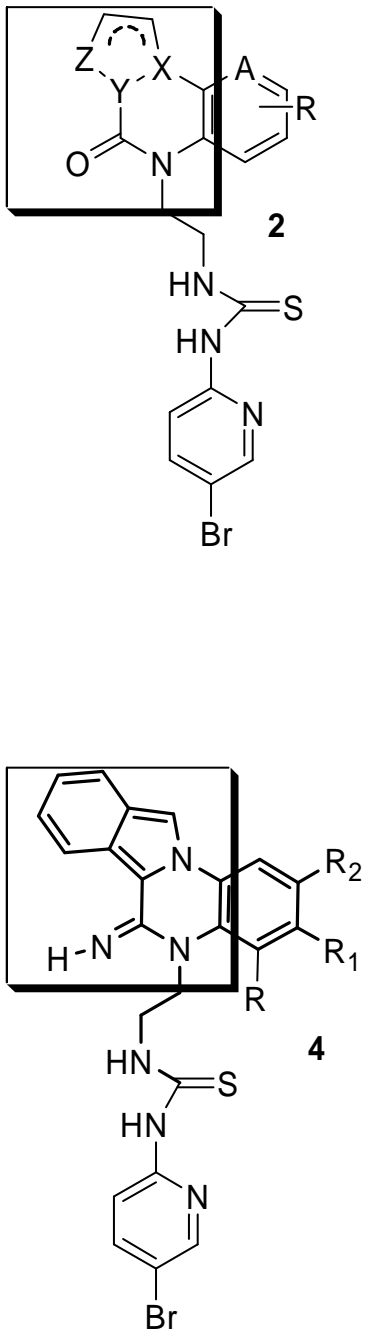

Figure 2. Quinoxalinylethylpyridylthioureas 1-4.

\section{Results and Discussion}

The key intermediates for the synthesis of 1-(5-bromopyridin-2-yl)-3-[2-(isoindolo[2,1-a]quinoxalin-6-ylamino)ethyl]thiourea 3a-d and 1-(5-bromopyridin-2-yl)-3-[2-(6-iminoisoindolo[2,1-a]quinoxalin-5(6H)-yl)ethyl]thiourea derivatives 4a-d were the isoindolo[2,1-a]quinoxalin$6(5 H)$-imine acetates 5a-d prepared by us as previously reported ${ }^{38}$ (Scheme 1).

The reaction of the latter compounds with 2-azidoethyl-4-methylbenzenesulfonate $\mathbf{6}$, properly prepared from 2-chloroethanol with sodium azide and subsequent tosylation of the 
alcohol group, ${ }^{40}$ in dimethylformamide and in the presence of potassium carbonate as base, furnished both $N$-(2-azidoethyl)isoindolo[2,1-a]quinoxalin-6-amines 8a-d (40-45\%) and 5-(2azidoethyl)isoindolo[2,1-a]quinoxalin-6(5H)-imines 9a-d (46-51\%) separated by column chromatography (Scheme 1).

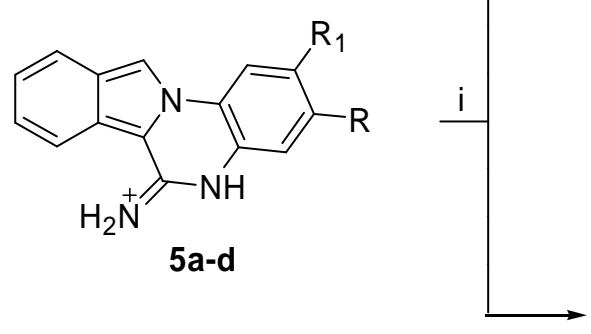<smiles></smiles><smiles>[R2]c1cc2c(c([R])c1[R])n(CCN)c(=N)c1c3ccccc3cn21</smiles>

a) $R=R_{1}=R_{2}=H$; b) $R=R_{2}=H, R_{1}=O M e$; c) $R=H, R_{1}=R_{2}=C l$; d) $R=M e, R_{1}=R_{2}=H$

Scheme 1. Reagents and conditions: (i) $\mathrm{K}_{2} \mathrm{CO}_{3}$, DMF, $2 \mathrm{~h}, \mathrm{rt}$, then 2-azidoethyl-4methylbenzenesulfonate $6,12 \mathrm{~h}, 90^{\circ} \mathrm{C}$.

The azidoethylquinoxalines 7a-d and 8a-d obtained were reduced to the corresponding amino compounds ${ }^{16}$ 9a-d and 10a-d in good yields (58-64\% and $62-78 \%$ respectively) using propane-1,3-dithiol and triethylamine (TEA) (Scheme 2). The subsequent functionalization of the obtained amino derivatives gave the desired 1-(5-bromopyridin-2-yl)-3-[2-(isoindolo[2,1a]quinoxalin-6-ylamino)ethyl]thiourea 3a-d (63-85\%) and 1-(5-bromopyridin-2-yl)-3-[2-(6iminoisoindolo[2,1-a]quinoxalin-5(6H)-yl)ethyl]thiourea 4a-d $(67-81 \%)$ derivatives by a coupling reaction in dimethylformamide with 5-bromo-2-isothiocyanatopyridine obtained from a reaction between 2-amino-5-bromopyridine and thiocarbonyldiimidazole in chloroform ${ }^{41}$ (Scheme 2). 


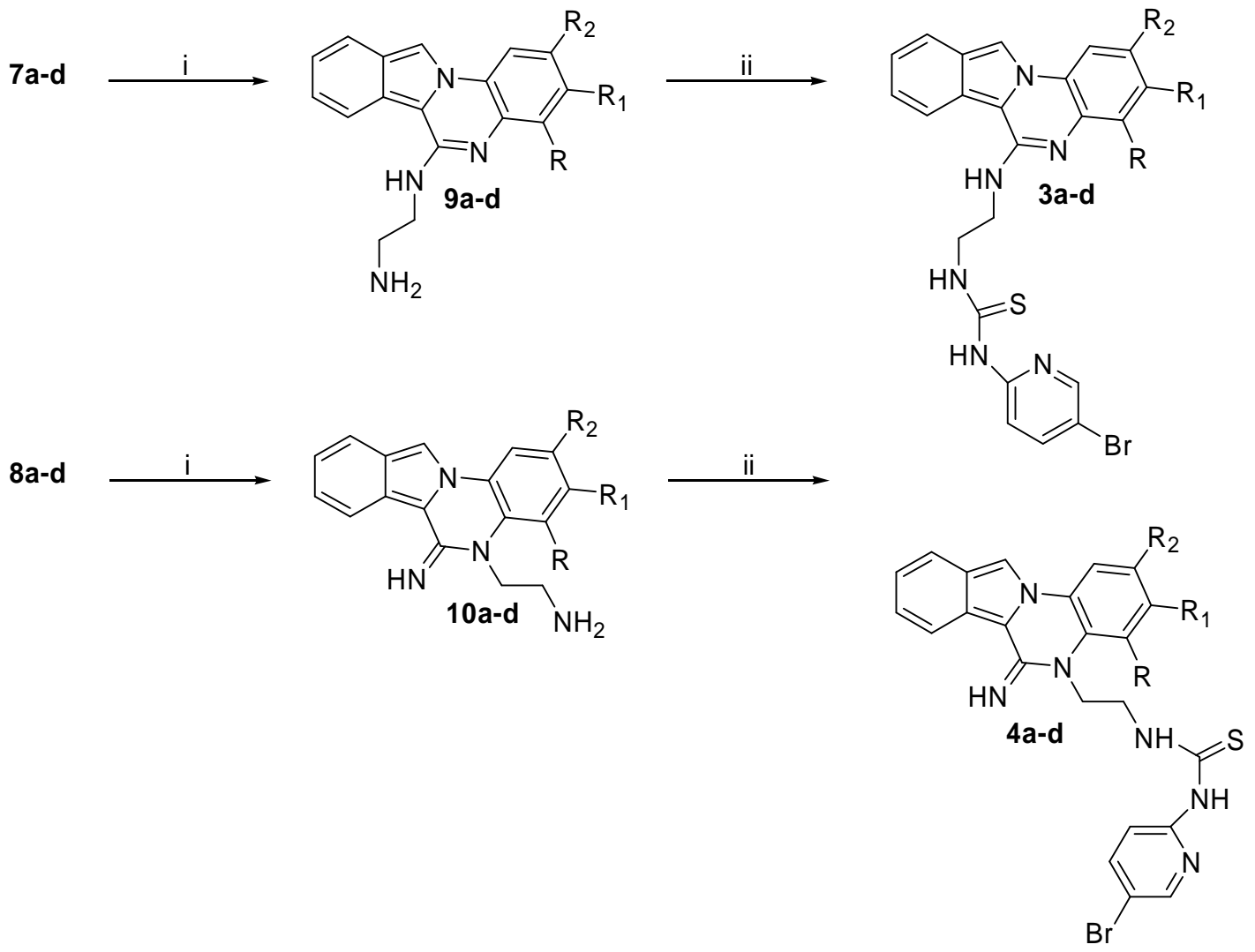

a) $R=R_{1}=R_{2}=H$; b) $R=R_{2}=H, R_{1}=O M e$; c) $R=H, R_{1}=R_{2}=C l$; d) $R=M e, R_{1}=R_{2}=H$

Scheme 2. Reagents and conditions: (i) TEA, propane-1,3-dithiol, $\mathrm{MeOH}, 24 \mathrm{~h}$, rt; (ii) 5-bromo-2isothiocyanatopyridine, DMF, $16 \mathrm{~h}, 100{ }^{\circ} \mathrm{C}$.

Furthermore, the antiviral activity of compounds $\mathbf{3}$ and $\mathbf{4}$ was assayed. In particular, their capacity to inhibit the activity of HIV-1 RT, was evaluated. Unfortunately, none of the derivatives 3 and $\mathbf{4}$ showed inhibition up to a concentration of $100 \mu \mathrm{M}$.

\section{Experimental Section}

General. All melting points were taken on a Büchi-Tottoly capillary apparatus and are uncorrected. IR spectra were determined in bromoform with a Shimadzu FT/IR 8400S spectrophotometer. ${ }^{1} \mathrm{H}$ and ${ }^{13} \mathrm{C}$ NMR spectra were measured at 200 and $50.0 \mathrm{MHz}$, respectively, in DMSO- $d_{6}$ or $\mathrm{CDCl}_{3}$ solution, using a Bruker Avance II series $200 \mathrm{MHz}$ spectrometer. Column chromatography was performed with Merk silica gel 230-400 mesh ASTM or with Büchi Sepacor chromatography module (prepacked cartridge system). Elemental analyses (C, H, N) were within $\pm 0.4 \%$ of theoretical values and were performed with a VARIO EL III elemental analyzer. 
General procedure for the preparation of substituted $N$-(2-azidoethyl)isoindolo[2,1a]quinoxalin-6-amines (8a-d) and 5-(2-azidoethyl)isoindolo[2,1-a]quinoxalin-6(5H)-imines (9a-d). To a solution of isoindolo[2,1- $a$ ]quinoxalin-6(5H)-imine acetates 5a-d $\mathbf{- d}^{38}$ (2.10 mmol) in DMF $(7 \mathrm{~mL})$, potassium carbonate $(7.40 \mathrm{mmol}, 1.05 \mathrm{~g})$ was added and the reaction mixture was stirred for 2 hours at room temperature. Then 2 -azidoethyl-4-methylbenzenesulfonate $6^{40}(6.40$ mmol, $1.50 \mathrm{~g}$ ) was added and the mixture was heated at $90{ }^{\circ} \mathrm{C}$ for 12 hours. Water was added and the resulted solution was extracted with ethyl acetate $(3 \times 60 \mathrm{~mL})$, dried $\left(\mathrm{Na}_{2} \mathrm{SO}_{4}\right)$ and evaporated under reduced pressure. The obtained residue was purified by column chromatography to give corresponding derivatives 7a-d and $\mathbf{8 a - d}$.

$N$-(2-Azidoethyl)isoindolo[2,1-a]quinoxalin-6-amine (7a). The residue was purified by chromatography eluting with DCM. White solid; yield: $45 \%$; mp $156{ }^{\circ} \mathrm{C}$; IR $\left(\mathrm{CHBr}_{3}\right) \vee 3429$ $(\mathrm{NH}), 2257\left(\mathrm{~N}_{3}\right) \mathrm{cm}^{-1} ;{ }^{1} \mathrm{H}$ NMR $\left(200 \mathrm{MHz}, \mathrm{DMSO}-d_{6}\right) \delta 3.74-3.80\left(\mathrm{~m}, 2 \mathrm{H}, \mathrm{CH}_{2}\right), 4.80(\mathrm{t}, J 5.9$ $\left.\mathrm{Hz}, 2 \mathrm{H}, \mathrm{CH}_{2}\right), 7.45$ (d, J 8.0 Hz, 1H, Ar-H), 7.63 (d, J 8.0 Hz, 1H, Ar-H), 7.79-8.08 (m, 4H, ArH), $8.22(\mathrm{~d}, J 7.5 \mathrm{~Hz}, 1 \mathrm{H}, \mathrm{Ar}-\mathrm{H}), 8.41(\mathrm{~d}, J 7.7 \mathrm{~Hz}, 1 \mathrm{H}, \mathrm{Ar}-\mathrm{H}), 8.89$ (d, J 7.7 Hz, 1H, Ar-H), 11.20 (br, 1H, NH); ${ }^{13} \mathrm{C}$ NMR (50 MHz, DMSO-d $) \delta 39.6\left(\mathrm{CH}_{2}\right), 48.1\left(\mathrm{CH}_{2}\right), 127.1(\mathrm{C}), 127.5$ $(\mathrm{CH}), 127.6(\mathrm{CH}), 128.1(\mathrm{CH}), 128.6(\mathrm{CH}), 128.8(\mathrm{CH}), 129.8(\mathrm{CH}), 131.2(\mathrm{CH}), 131.7(\mathrm{CH})$, 132.4 (C), $133.7(\mathrm{CH}), 138.5(\mathrm{C}), 140.2(\mathrm{C}), 143.4(\mathrm{C}), 161.2(\mathrm{C})$. Anal. Calcd for $\mathrm{C}_{17} \mathrm{H}_{14} \mathrm{~N}_{6}$ : C, 67.54; H, 4.67; N, 27.80. Found: C, 67.38; H, 4.89; N, 27.64.

Further elution with DCM/Ethyl acetate $8 / 2$ gave 5-(2-azidoethyl)isoindolo[2,1-a]quinoxalin6(5H)-imines (8a). White solid; yield: 50\%; mp $165{ }^{\circ} \mathrm{C}$; IR $\left(\mathrm{CHBr}_{3}\right) \vee 3407(\mathrm{NH}), 2256\left(\mathrm{~N}_{3}\right)$ $1711(\mathrm{C}=\mathrm{NH}) \mathrm{cm}^{-1} ;{ }^{1} \mathrm{H} \mathrm{NMR}\left(200 \mathrm{MHz}, \mathrm{CDCl}_{3}\right) \delta 3.83\left(\mathrm{t}, J 4.9 \mathrm{~Hz}, 2 \mathrm{H}, \mathrm{CH}_{2}\right), 5.05(\mathrm{t}, J 4.9 \mathrm{~Hz}$, $\left.2 \mathrm{H}, \mathrm{CH}_{2}\right), 7.80-7.93(\mathrm{~m}, 4 \mathrm{H}, \mathrm{Ar}-\mathrm{H}), 8.01(\mathrm{td}, J 1.3,7.2 \mathrm{~Hz}, 1 \mathrm{H}, \mathrm{Ar}-\mathrm{H}), 8.28-8.35$ (m, 2H, Ar-H), $8.43(\mathrm{dd}, J 0.8,7.9 \mathrm{~Hz}, 1 \mathrm{H}, \mathrm{Ar}-\mathrm{H}), 9.26(\mathrm{dd}, J 0.8,7.9 \mathrm{~Hz}, 1 \mathrm{H}, \mathrm{Ar}-\mathrm{H}), 11.36(\mathrm{br}, 1 \mathrm{H}, \mathrm{NH}) ;{ }^{13} \mathrm{C}$ NMR $\left(50 \mathrm{MHz}, \mathrm{CDCl}_{3}\right) \delta 50.2\left(\mathrm{CH}_{2}\right), 66.5\left(\mathrm{CH}_{2}\right), 121.01(\mathrm{C}), 122.7(\mathrm{C}), 124.8(\mathrm{CH}), 125.4$ $(\mathrm{CH}), 129.2(\mathrm{CH}), 129.3(\mathrm{CH}), 129.4(\mathrm{CH}), 130.5(\mathrm{CH}), 130.8(\mathrm{CH}), 132.5(\mathrm{CH}), 134.9(\mathrm{C})$, $137.6(\mathrm{C}), 140.8(\mathrm{CH}), 141.3(\mathrm{C}), 143.3(\mathrm{C})$. Anal. Calcd for $\mathrm{C}_{17} \mathrm{H}_{14} \mathrm{~N}_{6}: \mathrm{C}, 67.54 ; \mathrm{H}, 4.67 ; \mathrm{N}$, 27.80. Found: C, 67.76; H, 4.32; N, 27.92.

$\mathbf{N}$-(2-Azidoethyl)-3-methoxyisoindolo[2,1-a]quinoxalin-6-amine (7b). The residue was purified by chromatography eluting with DCM/Ethyl acetate 9/1. White solid; yield: $43 \%$; mp $189{ }^{\circ} \mathrm{C}$; IR $\left(\mathrm{CHBr}_{3}\right)$ v $3480(\mathrm{NH}), 2256\left(\mathrm{~N}_{3}\right) \mathrm{cm}^{-1} ;{ }^{1} \mathrm{H}$ NMR $\left(200 \mathrm{MHz}, \mathrm{DMSO}-d_{6}\right) \delta 3.75-3.81$ (m, 2H, $\mathrm{CH}_{2}$ ), 3.99 (s, 3H, $\mathrm{OCH}_{3}$ ), 4.79 (t, J $6.0 \mathrm{~Hz}, 2 \mathrm{H}, \mathrm{CH}_{2}$ ), 7.40-7.50 (m, 2H, Ar-H), 7.828.08 (m, 4H, Ar-H), 8.39 (dd, J 0.9, 7.1 Hz, 1H, Ar-H), 8.84 (dd, J 0.9, 7.1 Hz, 1H, Ar-H), 11.18 (br, 1H, NH); ${ }^{13} \mathrm{C}$ NMR (50 MHz, DMSO-d $) \delta 39.5\left(\mathrm{CH}_{2}\right), 48.1\left(\mathrm{CH}_{2}\right), 56.0\left(\mathrm{CH}_{3}\right), 105.7(\mathrm{CH})$, $121.7(\mathrm{CH}), 123.6(\mathrm{CH}), 126.5(\mathrm{C}), 128.0(\mathrm{CH}), 130.0(\mathrm{CH}), 130.9(\mathrm{CH}), 132.6(\mathrm{C}), 132.7(\mathrm{C})$, 133.6 (CH), $134.6(\mathrm{C}), 139.9(\mathrm{CH}), 142.3(\mathrm{C}), 161.3(\mathrm{C}), 161.5(\mathrm{C})$. Anal. Calcd for $\mathrm{C}_{18} \mathrm{H}_{16} \mathrm{~N}_{6} \mathrm{O}$ : C, 65.05; H, 4.85; N, 25.29. Found: C, 64.81; H, 4.69; N, 25.50.

Further elution with DCM/Ethyl acetate $8 / 2$ gave 5-(2-azidoethyl)-3-methoxyisoindolo[2,1a]quinoxalin-6(5H)-imine (8b). White solid; yield: $46 \%$; mp $189{ }^{\circ} \mathrm{C}$; IR $\left(\mathrm{CHBr}_{3}\right)$ v $3021(\mathrm{NH})$, $2104\left(\mathrm{~N}_{3}\right), 1695(\mathrm{C}=\mathrm{NH}) \mathrm{cm}^{-1} ;{ }^{1} \mathrm{H}$ NMR $\left(200 \mathrm{MHz}, \mathrm{CDCl}_{3}\right) \delta 3.83\left(\mathrm{t}, J 6.0 \mathrm{~Hz}, 2 \mathrm{H}, \mathrm{CH}_{2}\right), 4.02$ $\left(\mathrm{s}, 3 \mathrm{H}, \mathrm{OCH}_{3}\right), 5.08$ (t, J $\left.6.0 \mathrm{~Hz}, 2 \mathrm{H}, \mathrm{CH}_{2}\right), 7.46-7.55$ (m, 2H, 2 x Ar-H), 7.80-8.02 (m, 3H, 3 x 
Ar-H), 8.18 (d, J 9.1 Hz, 1H, Ar-H), 8.41 (d, J 8.0 Hz, 1H, Ar-H), 9.19 (d, J 8.0 Hz, 1H, Ar-H), $11.34(\mathrm{br}, 1 \mathrm{H}, \mathrm{NH}) ;{ }^{13} \mathrm{C} \mathrm{NMR}\left(50 \mathrm{MHz}, \mathrm{CDCl}_{3}\right) \delta 29.7\left(\mathrm{CH}_{2}\right), 50.2\left(\mathrm{CH}_{2}\right), 55.8\left(\mathrm{CH}_{3}\right), 105.6$ $(\mathrm{CH}), 122.1(\mathrm{C}), 123.8(\mathrm{CH}), 124.2(\mathrm{CH}), 124.5(\mathrm{C}), 125.3(\mathrm{CH}), 129.0(\mathrm{CH}), 130.1(\mathrm{CH}), 130.3$ (CH), $132.4(\mathrm{CH}), 135.0(\mathrm{C}), 135.4(\mathrm{C}), 137.9$ (C), 145.1 (C), 161.4 (C). Anal. Calcd for $\mathrm{C}_{18} \mathrm{H}_{16} \mathrm{~N}_{6} \mathrm{O}: \mathrm{C}, 65.05 ; \mathrm{H}, 4.85 ; \mathrm{N}, 25.29$. Found: $\mathrm{C}, 64.75 ; \mathrm{H}, 5.12 ; \mathrm{N}, 25.41$.

$\mathrm{N}$-(2-Azidoethyl)-2,3-dichloroisoindolo[2,1-a]quinoxalin-6-amine (7c). The residue was purified by chromatography eluting with DCM/Ethyl acetate $9 / 1$. White solid; yield: $40 \%$; mp $152{ }^{\circ} \mathrm{C}$; IR $\left(\mathrm{CHBr}_{3}\right)$ v $3429(\mathrm{NH}), 2256\left(\mathrm{~N}_{3}\right) \mathrm{cm}^{-1}$; ${ }^{1} \mathrm{H} \mathrm{NMR}\left(200 \mathrm{MHz}, \mathrm{CDCl}_{3}\right) \delta$ 3.73-3.80 (m, $2 \mathrm{H}, \mathrm{CH}_{2}$ ), 4.92 (t, J $\left.6.3 \mathrm{~Hz}, 2 \mathrm{H}, \mathrm{CH}_{2}\right), 7.83-7.93$ (m, 3H, Ar-H), 8.21 (s, 1H, Ar-H), 8.33 (s, 1H, Ar-H), 8.52 (d, J 7.7 Hz, 1H, Ar-H), 8.95 (d, J 7.7 Hz, 1H, Ar-H), 11.19 (br, 1H, NH); ${ }^{13} \mathrm{C}$ NMR $\left(50 \mathrm{MHz}, \mathrm{CDCl}_{3}\right) \delta 39.9\left(\mathrm{CH}_{2}\right), 47.6\left(\mathrm{CH}_{2}\right), 124.8(\mathrm{CH}), 125.1(\mathrm{C}), 127.5(\mathrm{C}), 128.6(\mathrm{CH}), 128.8$ $(\mathrm{CH}), 129.6(\mathrm{CH}), 131.8(\mathrm{CH}), 131.9(\mathrm{CH}), 132.4(\mathrm{C}), 133.7(\mathrm{CH}), 135.5(\mathrm{C}), 139.5(\mathrm{C}), 139.7$ (C), 158.6 (C), 161.9 (C). Anal. Calcd for $\mathrm{C}_{17} \mathrm{H}_{12} \mathrm{Cl}_{2} \mathrm{~N}_{6}$ : C, 55.00; H, 3.26; N, 22.64. Found: C, 54.79; H, 3.42; N, 22.43.

Further elution with DCM/Ethyl acetate $8 / 2$ gave 5-(2-azidoethyl)-2,3-dichloroisoindolo[2,1a]quinoxalin-6(5H)-imine (8c). White solid; yield: 51\%; mp $169^{\circ} \mathrm{C}$; IR $\left(\mathrm{CHBr}_{3}\right)$ v $3409(\mathrm{NH})$, $2105\left(\mathrm{~N}_{3}\right), 1722(\mathrm{C}=\mathrm{NH}) \mathrm{cm}^{-1} ;{ }^{1} \mathrm{H} \mathrm{NMR}\left(200 \mathrm{MHz}, \mathrm{CDCl}_{3}\right) \delta 3.83\left(\mathrm{t}, J 4.9 \mathrm{~Hz}, 2 \mathrm{H}, \mathrm{CH}_{2}\right), 5.03$ (t, J 4.9 Hz, 2H, $\mathrm{CH}_{2}$ ), 7.83-8.06 (m, 3H, Ar-H), 8.36-8.43 (m, 3H, Ar-H), 9.18 (dd, J 1.2, 8.0 $\mathrm{Hz}, 1 \mathrm{H}, \mathrm{Ar}-\mathrm{H}), 11.35$ (br, $1 \mathrm{H}, \mathrm{NH}) ;{ }^{13} \mathrm{C} \mathrm{NMR}\left(50 \mathrm{MHz}, \mathrm{CDCl}_{3}\right) \delta 50.1\left(\mathrm{CH}_{2}\right), 66.7\left(\mathrm{CH}_{2}\right), 122.8$ $(\mathrm{CH}), 124.9(\mathrm{CH}), 125.5(\mathrm{CH}), 129.4(\mathrm{CH}), 129.6(\mathrm{CH}), 131.4(\mathrm{CH}), 132.8(\mathrm{CH}), 133.9(\mathrm{C})$, 134.5 (C), 135.2 (C), 138.5 (C), 139.7 (C), 141.8 (C), 148.0 (C), 163.5 (C). Anal. Calcd for $\mathrm{C}_{17} \mathrm{H}_{12} \mathrm{Cl}_{2} \mathrm{~N}_{6}$ : C, 55.00; H, 3.26; N, 22.64. Found: C, 55.32; H, 3.48; N, 22.42.

$\mathrm{N}$-(2-Azidoethyl)-2-methylisoindolo[2,1-a]quinoxalin-6-amine (7d). The residue was purified by chromatography eluting with DCM/Ethyl acetate $9 / 1$. White solid; yield: $44 \%$; mp $147^{\circ} \mathrm{C}$; IR $\left(\mathrm{CHBr}_{3}\right)$ v $3391(\mathrm{NH}), 2257\left(\mathrm{~N}_{3}\right) \mathrm{cm}^{-1} ;{ }^{1} \mathrm{H} \mathrm{NMR}\left(200 \mathrm{MHz}, \mathrm{CDCl}_{3}\right) \delta 2.80\left(\mathrm{~s}, 3 \mathrm{H}, \mathrm{CH}_{3}\right), 3.77-$ $3.83\left(\mathrm{~m}, 2 \mathrm{H}, \mathrm{CH}_{2}\right), 4.95$ (t, J 6.6 Hz, 2H, $\left.\mathrm{CH}_{2}\right), 7.58-7.68$ (m, 3H, Ar-H), 7.78 (td, J 1.4, 7.3 Hz, 1H, Ar-H), 7.90 (td, J 1.4, 7.3 Hz, 1H, Ar-H), 8.00-8.06 (m, 1H, Ar-H), 8.53 (dd, J 0.8, 7.9 Hz, $1 \mathrm{H}, \mathrm{Ar}-\mathrm{H}), 8.98(\mathrm{dd}, J 0.8,7.9 \mathrm{~Hz}, 1 \mathrm{H}, \mathrm{Ar}-\mathrm{H}), 11.20(\mathrm{br}, 1 \mathrm{H}, \mathrm{NH}) ;{ }^{13} \mathrm{C} \mathrm{NMR}\left(50 \mathrm{MHz}, \mathrm{CDCl}_{3}\right) \delta$ $17.3\left(\mathrm{CH}_{3}\right), 40.0\left(\mathrm{CH}_{2}\right), 48.5\left(\mathrm{CH}_{2}\right), 124.5(\mathrm{CH}), 127.0(\mathrm{CH}), 127.4(\mathrm{C}), 128.1(\mathrm{CH}), 128.2(\mathrm{CH})$, $128.6(\mathrm{CH}), 129.6(\mathrm{C}), 130.8(\mathrm{CH}), 131.2(\mathrm{CH}), 133.0(\mathrm{C}), 133.4(\mathrm{CH}), 136.2(\mathrm{C}), 139.6(\mathrm{C})$, 139.9 (C), 162.2 (C). Anal. Calcd for $\mathrm{C}_{18} \mathrm{H}_{16} \mathrm{~N}_{6}$ : C, 68.34; H, 5.10; N, 26.56. Found: C, 68.62; H, $4.86 ; \mathrm{N}, 26.82$.

Further elution with DCM/Ethyl acetate $8 / 2$ gave 5-(2-azidoethyl)-2-methylisoindolo[2,1a]quinoxalin-6(5H)-imine (8d). Yellow solid; yield: 50\%; mp $161{ }^{\circ} \mathrm{C}$; IR $\left(\mathrm{CHBr}_{3}\right) \vee 3442(\mathrm{NH})$, $2256\left(\mathrm{~N}_{3}\right), 1729(\mathrm{C}=\mathrm{NH}) \mathrm{cm}^{-1}$; ${ }^{1} \mathrm{H}$ NMR $\left(200 \mathrm{MHz}, \mathrm{CDCl}_{3}\right) \delta 2.98\left(\mathrm{~s}, 3 \mathrm{H}, \mathrm{CH}_{3}\right), 3.82(\mathrm{t}, J 4.9$ $\mathrm{Hz}, 2 \mathrm{H}, \mathrm{CH}_{2}$ ), 5.08 (t, J 4.9 Hz, 2H, $\mathrm{CH}_{2}$ ), 7.67-8.04 (m, 5H, Ar-H), 8.17 (dd, J 2.5, 7.5 Hz, 1H, Ar-H), 8.43 (dt, J 0.8, 8.0 Hz, 1H, Ar-H), 9.26 (dt, J 0.8, 8.0 Hz, 1H, Ar-H), 11.33 (br, 1H, NH); ${ }^{13} \mathrm{C} \mathrm{NMR}\left(50 \mathrm{MHz}, \mathrm{CDCl}_{3}\right) \delta 18.0\left(\mathrm{CH}_{3}\right), 50.3\left(\mathrm{CH}_{2}\right), 66.4\left(\mathrm{CH}_{2}\right), 122.6(\mathrm{CH}), 124.7(\mathrm{CH})$, $125.3(\mathrm{CH}), 127.2(\mathrm{CH}), 129.1(\mathrm{CH}), 130.2(\mathrm{CH}), 130.6(\mathrm{CH}), 132.4(\mathrm{CH}), 135.1(\mathrm{C}), 137.1(\mathrm{C})$, 
137.4 (C) 141.4 (C), 142.6 (C), 146.7 (C), 162.7 (C). Anal. Calcd for $\mathrm{C}_{18} \mathrm{H}_{16} \mathrm{~N}_{6}$ : C, 68.34; $\mathrm{H}$, 5.10; N, 26.56. Found: C, 68.72; H, 5.02; N, 26.73.

General procedure for the preparation of substituted $N$-(isoindolo[2,1-a]quinoxalin-6yl)ethane-1,2-diamines (9a-d) and 2-(6-iminoisoindolo[2,1-a]quinoxalin-5(6H)-yl)ethanamines (10a-d). To a mixture of propane-1,3-dithiol $(0.90 \mathrm{mmol}, 0.09 \mathrm{~mL})$ and triethylamine $(0.90 \mathrm{mmol}, 0.13 \mathrm{~mL})$ a solution of the proper $N$-(2-azidoethyl)isoindolo[2,1-a]quinoxalin-6amine 7a-d or 5-(2-azidoethyl)isoindolo[2,1-a]quinoxalin-6(5H)-imine 8a-d $(0.30 \mathrm{mmol})$ in anhydrous methanol $(3 \mathrm{~mL})$ was added under argon atmosphere. The reaction mixture was stirred at room temperature for 24 hours then the solvent was evaporated under reduced pressure and the obtained residue was purified by chromatography eluting with DCM/Ethyl acetate 8/2 to give derivatives 9a-d and 10a-d.

$\boldsymbol{N}$-(Isoindolo[2,1-a]quinoxalin-6-yl)ethane-1,2-diamine (9a). White solid; yield: 58\%; mp 177 ${ }^{\circ} \mathrm{C}$; IR $\left(\mathrm{CHBr}_{3}\right) \vee 3688,3557\left(\mathrm{NH}_{2}\right), 3370(\mathrm{NH}) \mathrm{cm}^{-1} ;{ }^{1} \mathrm{H}$ NMR $\left(200 \mathrm{MHz}, \mathrm{DMSO}-d_{6}\right) \delta 3.73-$ 3.79 (m, 2H, $\mathrm{CH}_{2}$ ), 4.78 (t, J 6.2 Hz, 2H, $\mathrm{CH}_{2}$ ), 7.77-8.07 (m, 6H, Ar-H), 8.20 (dd, J 1.3, 8.1 Hz, $1 \mathrm{H}, \mathrm{Ar}-\mathrm{H}), 8.39$ (dd, J 1.3, $8.1 \mathrm{~Hz}, 1 \mathrm{H}, \mathrm{Ar}-\mathrm{H}), 8.86$ (dd, J 1.0, $7.9 \mathrm{~Hz}, 1 \mathrm{H}, \mathrm{Ar}-\mathrm{H}), 11.23$ (br, $1 \mathrm{H}$, $\mathrm{NH}) ;{ }^{13} \mathrm{C}$ NMR $\left(50 \mathrm{MHz}, \mathrm{DMSO}-d_{6}\right) \delta 39.6\left(\mathrm{CH}_{2}\right), 48.1\left(\mathrm{CH}_{2}\right), 124.1(\mathrm{CH}), 127.1(\mathrm{C}), 127.5$ $(\mathrm{CH}), 127.6(\mathrm{C}), 128.1(\mathrm{CH}), 128.6(\mathrm{CH}), 128.8(\mathrm{CH}), 129.8(\mathrm{CH}), 131.2(\mathrm{CH}), 131.7(\mathrm{CH})$, $132.4(\mathrm{C}), 133.8(\mathrm{CH}), 138.6(\mathrm{C}), 140.3(\mathrm{C}), 161.2(\mathrm{C})$. Anal. Calcd for $\mathrm{C}_{17} \mathrm{H}_{16} \mathrm{~N}_{4}$ : C, 73.89; $\mathrm{H}$, 5.84; N, 20.27. Found: C, 74.15; H, 6.02; N, 20.53.

$\mathrm{N}$-(3-Methoxyisoindolo[2,1-a]quinoxalin-6-yl)ethane-1,2-diamine (9b). White solid; yield: 60\%; mp $192.4{ }^{\circ} \mathrm{C}$; IR $\left(\mathrm{CHBr}_{3}\right)$ v 3440, $3429\left(\mathrm{NH}_{2}\right), 3398(\mathrm{NH}) \mathrm{cm}^{-1} ;{ }^{1} \mathrm{H}$ NMR $(200 \mathrm{MHz}$, DMSO-d $\left.d_{6}\right) \delta 3.73-3.79\left(\mathrm{~m}, 2 \mathrm{H}, \mathrm{CH}_{2}\right), 3.97\left(\mathrm{~s}, 3 \mathrm{H}, \mathrm{OCH}_{3}\right), 4.75\left(\mathrm{t}, J 6.3 \mathrm{~Hz}, 2 \mathrm{H}, \mathrm{CH}_{2}\right), 7.32(\mathrm{~d}, J$ $2.8 \mathrm{~Hz}, 1 \mathrm{H}, \mathrm{Ar}-\mathrm{H}), 7.41$ (dd, J 2.8, 9.1 Hz, 1H, Ar-H), 7.79-8.06 (m, 4H, Ar-H), 8.35 (dd, $J 0.8$, $7.5 \mathrm{~Hz}, 1 \mathrm{H}, \mathrm{Ar}-\mathrm{H}), 8.77$ (dd, J 0.8, 7.5 Hz, 1H, Ar-H), $11.25(\mathrm{br}, 1 \mathrm{H}, \mathrm{NH}) ;{ }^{13} \mathrm{C} \mathrm{NMR}(50 \mathrm{MHz}$, DMSO-d $d_{6} \delta 56.0\left(\mathrm{CH}_{3}\right), 39.5\left(\mathrm{CH}_{2}\right), 48.1\left(\mathrm{CH}_{2}\right), 105.6(\mathrm{CH}), 121.7(\mathrm{CH}), 123.6(\mathrm{CH}), 126.5$ $(\mathrm{C}), 128.0(\mathrm{CH}), 128.7(\mathrm{CH}), 130.0(\mathrm{CH}), 130.9(\mathrm{CH}), 132.6(\mathrm{C}), 132.7(\mathrm{C}), 133.6(\mathrm{CH}), 134.6$ (C), 142.2 (C), 143.6 (C), 161.5 (C). Anal. Calcd for $\mathrm{C}_{18} \mathrm{H}_{18} \mathrm{~N}_{4} \mathrm{O}$ : C, 70.57; H, 5.92; N, 18.29. Found: C, 70.32; H, 5.62; N, 18.52 .

$N$-(2,3-Dichloroisoindolo[2,1-a]quinoxalin-6-yl)ethane-1,2-diamine (9c). Brown solid; yield: 60\%; mp $164{ }^{\circ} \mathrm{C}$; IR $\left(\mathrm{CHBr}_{3}\right)$ v 3671, $3584\left(\mathrm{NH}_{2}\right), 3419(\mathrm{NH}) \mathrm{cm}^{-1} ;{ }^{1} \mathrm{H}$ NMR $\left(200 \mathrm{MHz}, \mathrm{CDCl}_{3}\right)$ $\delta$ 3.76-3.80 (m, 2H, CH $), 4.92\left(\mathrm{t}, J 6.4 \mathrm{~Hz}, 2 \mathrm{H}, \mathrm{CH}_{2}\right), 7.78-7.97(\mathrm{~m}, 3 \mathrm{H}, \mathrm{Ar}-\mathrm{H}), 8.20(\mathrm{~s}, 1 \mathrm{H}$, Ar-H), 8.32 (s, 1H, Ar-H), 8.54 (dd, J 1.2, $7.4 \mathrm{~Hz}, 1 \mathrm{H}, \mathrm{Ar}-\mathrm{H}), 8.92$ (d, J 1.2 Hz, 1H, Ar-H), 11.25 (br, $1 \mathrm{H}, \mathrm{NH}) ;{ }^{13} \mathrm{C}$ NMR $\left(50 \mathrm{MHz}, \mathrm{CDCl}_{3}\right) \delta 40.0\left(\mathrm{CH}_{2}\right), 48.7\left(\mathrm{CH}_{2}\right), 119.1(\mathrm{C}), 124.8$ $(\mathrm{CH}), 127.5(\mathrm{C}), 128.6(\mathrm{CH}), 128.8(\mathrm{CH}), 129.5(\mathrm{CH}), 129.6(\mathrm{CH}), 131.9(\mathrm{CH}), 132.4(\mathrm{C}), 132.9$ (C), 133.7 (CH), 135.5 (C), 138.1 (C), 139.7 (C), 161.9 (C). Anal. Calcd for $\mathrm{C}_{17} \mathrm{H}_{14} \mathrm{Cl}_{2} \mathrm{~N}_{4}$ : C, 59.14; H, 4.09; N, 16.23. Found: C, 58.86; H, 4.15; N, 16.47 .

$\mathrm{N}$-(2-Methylisoindolo[2,1-a]quinoxalin-6-yl)ethane-1,2-diamine (9d). Yellow solid; yield: 64\%; mp $168{ }^{\circ} \mathrm{C}$; IR $\left(\mathrm{CHBr}_{3}\right)$ v 3689, $3567\left(\mathrm{NH}_{2}\right), 3372(\mathrm{NH}) \mathrm{cm}^{-1} ;{ }^{1} \mathrm{H}$ NMR $(200 \mathrm{MHz}$, DMSO-d $\left.d_{6}\right) \delta 2.73\left(\mathrm{~s}, 3 \mathrm{H}, \mathrm{CH}_{3}\right), 3.78-3.83\left(\mathrm{~m}, 2 \mathrm{H}, \mathrm{CH}_{2}\right), 4.78\left(\mathrm{t}, J 6.4 \mathrm{~Hz}, 2 \mathrm{H}, \mathrm{CH}_{2}\right), 7.62-8.05$ (m, 6H, Ar-H), 8.40 (dd, J 0.9, $7.8 \mathrm{~Hz}, 1 \mathrm{H}, \mathrm{Ar}-\mathrm{H}), 8.85$ (dd, J 0.9, 7.8 Hz, 1H, Ar-H), 11.24 (br, 
$1 \mathrm{H}, \mathrm{NH}) ;{ }^{13} \mathrm{C}$ NMR $\left(50 \mathrm{MHz}, \mathrm{DMSO}-d_{6}\right) \delta 16.7\left(\mathrm{CH}_{3}\right), 39.6\left(\mathrm{CH}_{2}\right), 47.8\left(\mathrm{CH}_{2}\right), 124.0(\mathrm{CH})$, $126.6(\mathrm{CH}), 127.1(\mathrm{C}), 127.5(\mathrm{CH}), 128.2(\mathrm{CH}), 129.8(\mathrm{CH}), 130.8(\mathrm{CH}), 131.5(\mathrm{CH}), 132.3(\mathrm{C})$, $133.6(\mathrm{CH}), 135.5(\mathrm{C}), 138.5(\mathrm{C}), 139.1(\mathrm{C}), 142.2(\mathrm{C}), 161.1(\mathrm{C})$. Anal. Calcd for $\mathrm{C}_{18} \mathrm{H}_{18} \mathrm{~N}_{4}$ : C, 74.46; H, 6.25; N, 19.30. Found: C, 74.72; H, 6.01; N, 19.07.

2-(6-Iminoisoindolo[2,1-a] quinoxalin-5(6H)-yl)ethanamine (9a). White solid; yield: $72 \%$; mp $194{ }^{\circ} \mathrm{C}$; IR $\left(\mathrm{CHBr}_{3}\right)$ v 3679, $3556\left(\mathrm{NH}_{2}\right), 3393(\mathrm{NH}), 1719(\mathrm{C}=\mathrm{NH}) \mathrm{cm}^{-1} ;{ }^{1} \mathrm{H}$ NMR $(200 \mathrm{MHz}$, $\left.\mathrm{CDCl}_{3}\right) \delta 3.83\left(\mathrm{t}, J 4.9 \mathrm{~Hz}, 2 \mathrm{H}, \mathrm{CH}_{2}\right), 5.05\left(\mathrm{t}, J 4.9 \mathrm{~Hz}, 2 \mathrm{H}, \mathrm{CH}_{2}\right), 7.80-7.92(\mathrm{~m}, 4 \mathrm{H}, \mathrm{Ar}-\mathrm{H}), 8.01$ (td, $J 1.4,7.3 \mathrm{~Hz}, 1 \mathrm{H}$, Ar-H), 8.27-8.35 (m, 2H, Ar-H), 8.43 (dd, $J$ 0.8, $7.9 \mathrm{~Hz}, 1 \mathrm{H}$, Ar-H), 9.25 $(\mathrm{dd}, J 0.8,7.9 \mathrm{~Hz}, 1 \mathrm{H}, \mathrm{Ar}-\mathrm{H}), 11.32(\mathrm{br}, 1 \mathrm{H}, \mathrm{NH}) ;{ }^{13} \mathrm{C} \mathrm{NMR}\left(50 \mathrm{MHz}, \mathrm{CDCl}_{3}\right) \delta 50.2\left(\mathrm{CH}_{2}\right)$, $66.5\left(\mathrm{CH}_{2}\right), 124.6(\mathrm{CH}), 125.2(\mathrm{CH}), 125.3(\mathrm{CH}), 129.1(\mathrm{C}), 129.2(\mathrm{C}), 129.2(\mathrm{CH}), 129.3(\mathrm{CH})$, $129.4(\mathrm{CH}), 129.5(\mathrm{C}), 129.7(\mathrm{C}), 130.4(\mathrm{CH}), 130.9(\mathrm{CH}), 132.2(\mathrm{C}), 132.8(\mathrm{CH}), 136.8(\mathrm{C})$. Anal. Calcd for $\mathrm{C}_{17} \mathrm{H}_{16} \mathrm{~N}_{4}$ : C, 73.89; H, 5.84; N, 20.27. Found: C, 73.96; H, 6.01; N, 19.93 .

2-(6-Imino-3-methoxyisoindolo[2,1-a]quinoxalin-5(6H)-yl)ethanamine (9b). White solid; yield: 62\%; mp $198.8{ }^{\circ} \mathrm{C}$; IR $\left(\mathrm{CHBr}_{3}\right)$ v 3584, $3437\left(\mathrm{NH}_{2}\right), 3319(\mathrm{NH}), 1666(\mathrm{C}=\mathrm{NH}) \mathrm{cm}^{-1} ;{ }^{1} \mathrm{H}$ NMR (200 MHz, DMSO-d $\left.d_{6}\right) \delta 3.77\left(\mathrm{t}, J 6.2 \mathrm{~Hz}, 2 \mathrm{H}, \mathrm{CH}_{2}\right), 3.98\left(\mathrm{~s}, 3 \mathrm{H}, \mathrm{OCH}_{3}\right), 4.77$ (t, $J 6.2 \mathrm{~Hz}$, 2H, $\mathrm{CH}_{2}$ ), 7.35-7.46 (m, 2H, Ar-H), 7.70-8.09 (m, 4H, 4 x Ar-H), 8.37 (d, J 7.5 Hz, 1H, Ar-H), $8.80(\mathrm{~d}, J 7.5 \mathrm{~Hz}, 1 \mathrm{H}, \mathrm{Ar}-\mathrm{H}), 11.30(\mathrm{br}, 1 \mathrm{H}, \mathrm{NH}) ;{ }^{13} \mathrm{C}$ NMR $\left(50 \mathrm{MHz}, \mathrm{DMSO}-d_{6}\right) \delta 39.5\left(\mathrm{CH}_{2}\right)$, $48.1\left(\mathrm{CH}_{2}\right), 56.0\left(\mathrm{CH}_{3}\right), 105.6(\mathrm{CH}), 121.6(\mathrm{CH}), 123.6(\mathrm{CH}), 126.4(\mathrm{C}), 128.0(\mathrm{CH}), 129.9$ $(\mathrm{CH}), 130.9(\mathrm{CH}), 131.7(\mathrm{CH}), 132.5(\mathrm{C}), 132.6(\mathrm{C}), 133.6(\mathrm{CH}), 134.5(\mathrm{C}), 142.2(\mathrm{C}), 143.6$ (C), 161.2 (C). Anal. Calcd for $\mathrm{C}_{18} \mathrm{H}_{18} \mathrm{~N}_{4} \mathrm{O}: \mathrm{C}, 70.57 ; \mathrm{H}, 5.92 ; \mathrm{N}, 18.29$. Found: C, 70.83; H, $5.68 ; \mathrm{N}, 18.01$.

2-(2,3-Dichloro-6-iminoisoindolo[2,1-a]quinoxalin-5(6H)-yl)ethanamine (9c). Brown solid; yield: 78\%; mp $182{ }^{\circ} \mathrm{C}$; IR $\left(\mathrm{CHBr}_{3}\right)$ v 3679, $3558\left(\mathrm{NH}_{2}\right), 3393(\mathrm{NH}), 1719(\mathrm{C}=\mathrm{NH}) \mathrm{cm}^{-1}$; ${ }^{1} \mathrm{H}$ NMR (200 MHz, DMSO-d $) \delta 3.92\left(\mathrm{t}, J 5.0 \mathrm{~Hz}, 2 \mathrm{H}, \mathrm{CH}_{2}\right), 4.90\left(\mathrm{t}, J 5.0 \mathrm{~Hz}, 2 \mathrm{H}, \mathrm{CH}_{2}\right), 7.94-$ 8.14 (m, 3H, Ar-H), 8.35 (d, J 8.1 Hz, 1H, Ar-H), 8.47 (s, 1H, Ar-H), 8.57 (s, 1H, Ar-H), 9.05 (d, $J 8.1 \mathrm{~Hz}, 1 \mathrm{H}, \mathrm{Ar}-\mathrm{H}), 11.31(\mathrm{br}, 1 \mathrm{H}, \mathrm{NH}) ;{ }^{13} \mathrm{C} \mathrm{NMR}\left(50 \mathrm{MHz}, \mathrm{DMSO}-d_{6}\right) \delta 50.1\left(\mathrm{CH}_{2}\right), 66.8$ $\left(\mathrm{CH}_{2}\right), 122.9(\mathrm{C}), 124.9(\mathrm{CH}), 125.6(\mathrm{CH}), 129.4(\mathrm{CH}), 129.7(\mathrm{CH}), 131.4(\mathrm{CH}), 132.9(\mathrm{CH})$, 133.9 (C), 134.5 (C), 135.2 (C), 139.8 (C), 141.8 (C), 143.1 (CH), 163.6 (C), 164.5 (C). Anal. Calcd for $\mathrm{C}_{17} \mathrm{H}_{14} \mathrm{Cl}_{2} \mathrm{~N}_{4}$ : C, 59.14; H, 4.09; N, 16.23. Found: C, 59.41; H, 4.36; N, 16.02.

2-(6-Imino-2-methylisoindolo[2,1-a]quinoxalin-5(6H)-yl)ethanamine (9d). Yellow solid; yield: 64\%; mp $189.6{ }^{\circ} \mathrm{C}$; IR $\left(\mathrm{CHBr}_{3}\right) \vee 3604,3501\left(\mathrm{NH}_{2}\right), 3407(\mathrm{NH}), 1713(\mathrm{C}=\mathrm{NH}) \mathrm{cm}^{-1}$; ${ }^{1} \mathrm{H}$ NMR $\left(200 \mathrm{MHz}, \mathrm{CDCl}_{3}\right) \delta 2.98\left(\mathrm{~s}, 3 \mathrm{H}, \mathrm{CH}_{3}\right), 3.82\left(\mathrm{t}, J 4.9 \mathrm{~Hz}, 2 \mathrm{H}, \mathrm{CH}_{2}\right), 5.08(\mathrm{t}, J 4.9 \mathrm{~Hz}, 2 \mathrm{H}$, $\mathrm{CH}_{2}$ ), 7.60-7.80 (m, 3H, Ar-H), 7.87 (td, $\left.J 2.4,7.4 \mathrm{~Hz}, 1 \mathrm{H}, \mathrm{Ar}-\mathrm{H}\right), 8.00$ (td, $J 1.4,7.9 \mathrm{~Hz}, 1 \mathrm{H}$, Ar-H), 8.17 (dd, J 2.4, $7.4 \mathrm{~Hz}, 1 \mathrm{H}$, Ar-H), 8.43 (dd, J 1.3, $8.1 \mathrm{~Hz}, 1 \mathrm{H}$, Ar-H), 9.25 (d, J 7.8 Hz, $1 \mathrm{H}, \mathrm{Ar}-\mathrm{H}), 11.39(\mathrm{br}, 1 \mathrm{H}, \mathrm{NH}) ;{ }^{13} \mathrm{C} \mathrm{NMR}\left(50 \mathrm{MHz}, \mathrm{CDCl}_{3}\right) \delta 18.0\left(\mathrm{CH}_{3}\right), 29.7\left(\mathrm{CH}_{2}\right), 50.3$ $\left(\mathrm{CH}_{2}\right), 122.6(\mathrm{CH}), 124.7(\mathrm{CH}), 125.3(\mathrm{CH}), 127.2(\mathrm{CH}), 129.1(\mathrm{CH}), 130.2(\mathrm{CH}), 130.6(\mathrm{CH})$, $132.4(\mathrm{CH}), 135.0(\mathrm{C}), 137.1(\mathrm{C}), 137.4(\mathrm{C}), 141.4(\mathrm{C}), 142.6$ (C), 146.7 (C), 162.8 (C). Anal. Calcd for $\mathrm{C}_{18} \mathrm{H}_{18} \mathrm{~N}_{4}$ : C, 74.46; H, 6.25; N, 19.30. Found: C, 74.82; H, 6.17; N, 19.01.

General procedure for the preparation of substituted 1-(5-bromopyridin-2-yl)-3-[2(isoindolo[2,1-a]quinoxalin-6-ylamino)ethyl]thioureas (3a-d) and 1-(5-bromopyridin-2-yl)- 
3-[2-(6-iminoisoindolo[2,1-a]quinoxalin-5(6H)-yl)ethyl]thioureas (4a-d). To a suspension of 5-bromo-2-isothiocyanatopyridine ${ }^{41}(4.0 \mathrm{mmol})$ in DMF $(15 \mathrm{~mL})$ the suitable $\mathrm{N}$-(isoindolo[2,1a]quinoxalin-6-yl)ethane-1,2-diamine 9a-d or 2-(6-iminoisoindolo[2,1-a]quinoxalin-5(6H)yl)ethanamine 10a-d $(1.0 \mathrm{mmol})$ was added and the reaction was stirred at $100{ }^{\circ} \mathrm{C}$ for 16 hours. Then the reaction mixture was cooled to room temperature, poured into iced water and the resulting precipitate collected by filtration. The crude obtained was purified by column chromatography to give derivatives 3a-d and 4a-d.

1-(5-Bromopyridin-2-yl)-3-[2-(isoindolo[2,1-a]quinoxalin-6-ylamino)ethyl]thiourea (3a). The residue eluted with DCM/Ethyl acetate 9/1. White solid; yield: $65 \%$; mp $198{ }^{\circ} \mathrm{C}$; IR $\left(\mathrm{CHBr}_{3}\right) \vee 3678(\mathrm{NH}), 3563(\mathrm{NH}), 3403(\mathrm{NH}), 1328(\mathrm{C}=\mathrm{S}) \mathrm{cm}^{-1}$; ${ }_{1}^{1} \mathrm{H}$ NMR (200 MHz, DMSO$\left.d_{6}\right) \delta$ 4.19-4.22 (m, 2H, CH 2$), 4.89-4.91\left(\mathrm{~m}, 2 \mathrm{H}, \mathrm{CH}_{2}\right), 6.76(\mathrm{~d}, J 9.1 \mathrm{~Hz}, 1 \mathrm{H}, \mathrm{Ar}-\mathrm{H}), 7.67-7.69$ (m, 2H, Ar-H), 7.71-7.87 (m, 3H, Ar-H), 7.84-7.92 (m, 2H, Ar-H), 7.99-8.03 (m, 1H, Ar-H), 8.06-8.13 (m, 1H, Ar-H), 8.35 (d, J 7.5 Hz, 1H, Ar-H), 8.89 (d, J 7.5 Hz, 1H, Ar-H), 10.42 (br, $1 \mathrm{H}, \mathrm{NH}), 10.62$ (br, 1H, NH), 11.21 (t, $J 4.9 \mathrm{~Hz}, 1 \mathrm{H}, \mathrm{NH}) ;{ }^{13} \mathrm{C}$ NMR (50 MHz, DMSO- $\left.d_{6}\right) \delta$ $40.3\left(\mathrm{CH}_{2}\right), 42.8\left(\mathrm{CH}_{2}\right), 111.5(\mathrm{C}), 113.8(\mathrm{CH}), 113.9(\mathrm{CH}), 124.0(\mathrm{CH}), 127.4(\mathrm{CH}), 127.9$ $(\mathrm{CH}), 128.2(\mathrm{CH}), 128.5(\mathrm{CH}), 130.7(\mathrm{CH}), 131.4(\mathrm{CH}), 132.4(\mathrm{C}), 133.4(\mathrm{CH}), 135.4(\mathrm{C}), 138.2$ (C), $140.0(\mathrm{C}), 140.7(\mathrm{CH}), 144.0(\mathrm{C}), 145.2(\mathrm{CH}), 151.7(\mathrm{C}), 161.4(\mathrm{C}), 180.0(\mathrm{C})$. Anal. Calcd for $\mathrm{C}_{23} \mathrm{H}_{19} \mathrm{BrN}_{6} \mathrm{~S}: \mathrm{C}, 56.22 ; \mathrm{H}, 3.90 ; \mathrm{N}, 17.10$. Found: C, 56.39; H, 3.76; N, 17.43.

1-(5-Bromopyridin-2-yl)-3-\{2-[(3-methoxyisoindolo[2,1-a]quinoxalin-6-yl)amino]ethyl\}

thiourea (3b). The residue eluted with DCM/Ethyl acetate 9/1. White solid; yield: 63\%; mp 239 ${ }^{\circ} \mathrm{C}$; IR $\left(\mathrm{CHBr}_{3}\right)$ v $3688(\mathrm{NH}), 3584(\mathrm{NH}), 3405(\mathrm{NH}), 1360(\mathrm{C}=\mathrm{S}) \mathrm{cm}^{-1} ;{ }^{1} \mathrm{H}$ NMR $(200 \mathrm{MHz}$, DMSO-d $\left.d_{6}\right) \delta .37\left(\mathrm{~s}, 3 \mathrm{H}, \mathrm{OCH}_{3}\right), 4.62-4.64\left(\mathrm{~m}, 2 \mathrm{H}, \mathrm{CH}_{2}\right), 5.30-5.36\left(\mathrm{~m}, 2 \mathrm{H}, \mathrm{CH}_{2}\right), 7.20(\mathrm{~d}, J 8.6$ Hz, 1H, Ar-H), 7.58 (d, J 2.7 Hz, 1H, Ar-H), 7.78 (dd, J 2.7, 8.6 Hz, 1H, Ar-H), 8.09-8.31 (m, 4H, Ar-H), 8.38-8.46 (m, 2H, Ar-H), 8.77 (d, J 7.9 Hz, 1H, Ar-H), 9.25 (d, J 7.9 Hz, 1H, Ar-H), 10.72 (br, 1H, NH), 10.86 (br, 1H, NH), 11.64 (t, J 4.7 Hz, 1H, NH); ${ }^{13} \mathrm{C}$ NMR (50 MHz, DMSO-d $d_{6} \delta 40.7\left(\mathrm{CH}_{2}\right), 43.9\left(\mathrm{CH}_{2}\right), 56.7\left(\mathrm{CH}_{3}\right), 106.2(\mathrm{CH}), 112.4(\mathrm{CH}), 114.8(\mathrm{CH}), 122.3$ $(\mathrm{CH}), 124.5(\mathrm{CH}), 127.7(\mathrm{C}), 128.8(\mathrm{CH}), 130.6(\mathrm{CH}), 131.6(\mathrm{CH}), 133.4(\mathrm{C}), 133.7(\mathrm{C}), 134.3$ $(\mathrm{CH}), 135.1(\mathrm{C}), 141.6(\mathrm{CH}), 142.9(\mathrm{C}), 145.1(\mathrm{C}), 146.1(\mathrm{CH}), 152.6(\mathrm{C}), 162.1(\mathrm{C}), 162.4(\mathrm{C})$, 180.9 (C). Anal. Calcd for $\mathrm{C}_{24} \mathrm{H}_{21} \mathrm{BrN}_{6} \mathrm{OS}: \mathrm{C}, 55.28 ; \mathrm{H}, 4.06 ; \mathrm{N}, 16.12$. Found: $\mathrm{C}, 55.52 ; \mathrm{H}$, $3.86 ; \mathrm{N}, 16.42$.

\section{1-(5-Bromopyridin-2-yl)-3-\{2-[(2,3-dichloroisoindolo[2,1-a]quinoxalin-6-yl)amino]ethyl\}}

thiourea (3c). The residue eluted with DCM. Pale yellow solid; yield: 85\%; mp $235{ }^{\circ} \mathrm{C}$; IR $\left(\mathrm{CHBr}_{3}\right) \vee 3671(\mathrm{NH}), 3558(\mathrm{NH}), 3414(\mathrm{NH}), 1311(\mathrm{C}=\mathrm{S}) \mathrm{cm}^{-1}$; ${ }^{1} \mathrm{H}$ NMR (200 MHz, DMSO$\left.d_{6}\right) \delta$ 4.19-4.23 (m, 2H, CH 2$), 4.86-4.88\left(\mathrm{~m}, 2 \mathrm{H}, \mathrm{CH}_{2}\right), 6.77(\mathrm{~d}, J 8.8 \mathrm{~Hz}, 1 \mathrm{H}, \mathrm{Ar}-\mathrm{H}), 7.68-7.75$ (m, 2H, Ar-H), 7.84 (s, 1H, Ar-H), 7.89-8.08 (m, 3H, Ar-H), 8.35-8.39 (m, 2H, Ar-H), 8.83 (d, J $7.7 \mathrm{~Hz}, 1 \mathrm{H}, \mathrm{Ar}-\mathrm{H}), 10.01$ (br, 1H, NH), 10.43 (br, 1H, NH), 11.18 (t, J 4.9 Hz, 1H, NH); ${ }^{13} \mathrm{C}$ NMR (50 MHz, DMSO- $\left.d_{6}\right) \delta 40.1\left(\mathrm{CH}_{2}\right), 42.9\left(\mathrm{CH}_{2}\right), 111.7(\mathrm{CH}), 113.8(\mathrm{CH}), 121.9(\mathrm{C}), 124.2$ $(\mathrm{CH}), 127.7(\mathrm{CH}), 127.9(\mathrm{CH}), 128.0(\mathrm{C}), 129.1(\mathrm{CH}), 129.4(\mathrm{C}), 130.5(\mathrm{C}), 131.9(\mathrm{C}), 132.1$ (CH), $133.2(\mathrm{C}), 133.6(\mathrm{CH}), 137.0(\mathrm{C}), 138.8(\mathrm{C}), 140.7(\mathrm{CH}), 145.1(\mathrm{C}), 145.2(\mathrm{CH}), 147.7$ 
(C), 181.7 (C). Anal. Calcd for $\mathrm{C}_{23} \mathrm{H}_{17} \mathrm{BrCl}_{2} \mathrm{~N}_{6} \mathrm{~S}$ : C, 49.30; H, 3.06; N, 15.00. Found: C, 49.02; $\mathrm{H}, 3.33 ; \mathrm{N}, 14.72$.

\section{1-(5-Bromopyridin-2-yl)-3-\{2-[(2-methylisoindolo[2,1-a]quinoxalin-6-yl)amino]ethyl\}}

thiourea (3d). The residue eluted with DCM/Ethyl acetate 98/2. Pale yellow solid; yield: 75\%; mp $230{ }^{\circ} \mathrm{C}$; IR $\left(\mathrm{CHBr}_{3}\right)$ v $3757(\mathrm{NH}), 3570(\mathrm{NH}), 3406(\mathrm{NH}), 1297(\mathrm{C}=\mathrm{S}) \mathrm{cm}^{-1} ;{ }^{1} \mathrm{H}$ NMR (200 MHz, DMSO- $d_{6}$ ) $\delta 2.71$ (s, 3H, $\mathrm{CH}_{3}$ ), 4.23-4.25 (m, 2H, $\mathrm{CH}_{2}$ ), 4.90-4.95 (m, 2H, $\mathrm{CH}_{2}$ ), 6.77 (d, $J 8.9 \mathrm{~Hz}, 1 \mathrm{H}, \mathrm{Ar}-\mathrm{H}), 7.44$ (d, J 2.4 Hz, 1H, Ar-H), 7.60-7.67 (m, 3H, Ar-H), 7.85-8.13 (m, 4H, Ar-H), 8.38 (d, J 7.8 Hz, 1H, Ar-H), 8.89 (d, J 7.9 Hz, 1H, Ar-H), 10.47 (br, 1H, NH), 10.62 (br, $1 \mathrm{H}, \mathrm{NH}), 11.12(\mathrm{t}, J 5.8 \mathrm{~Hz}, 1 \mathrm{H}, \mathrm{NH}) ;{ }^{13} \mathrm{C} \mathrm{NMR}\left(50 \mathrm{MHz}, \mathrm{DMSO}-d_{6}\right) \delta 16.7\left(\mathrm{CH}_{3}\right), 42.7\left(\mathrm{CH}_{2}\right)$, $59.7\left(\mathrm{CH}_{2}\right), 111.5(\mathrm{CH}), 113.8(\mathrm{CH}), 123.9(\mathrm{CH}), 126.2(\mathrm{CH}), 127.4(\mathrm{CH}), 127.9(\mathrm{CH}), 131.3$ $(\mathrm{CH}), 132.4(\mathrm{CH}), 133.4(\mathrm{CH}), 134.9(\mathrm{C}), 135.5(\mathrm{C}), 138.2(\mathrm{C}), 139.0(\mathrm{C}), 140.7(\mathrm{CH}), 141.4$ (C), 142.9 (C), 144.9 (CH), 151.6 (C), 161.4 (C), 170.3 (C), 179.9 (C). Anal. Calcd for $\mathrm{C}_{24} \mathrm{H}_{21} \mathrm{BrN}_{6} \mathrm{~S}$ : C, 57.03; H, 4.19; N, 16.63. Found: C, 56.82; H, 4.49; N, 16.32 .

1-(5-Bromopyridin-2-yl)-3-[2-(6-iminoisoindolo[2,1-a]quinoxalin-5(6H)-yl)ethyl]thiourea (4a). The residue eluted with DCM/Ethyl acetate $9 / 1$. Pale yellow solid; yield: $68 \%$; $\mathrm{mp} 205^{\circ} \mathrm{C}$; IR $\left(\mathrm{CHBr}_{3}\right) \vee 3670(\mathrm{NH}), 3557(\mathrm{NH}), 1704(\mathrm{C}=\mathrm{NH}), 1323(\mathrm{C}=\mathrm{S}) \mathrm{cm}^{-1} ;{ }^{1} \mathrm{H}$ NMR $(200 \mathrm{MHz}$, DMSO- $\left.d_{6}\right) \delta 3.74-3.80\left(\mathrm{~m}, 2 \mathrm{H}, \mathrm{CH}_{2}\right), 4.80\left(\mathrm{t}, J 6.1 \mathrm{~Hz}, 2 \mathrm{H}, \mathrm{CH}_{2}\right), 7.38(\mathrm{~d}, J 8.0 \mathrm{~Hz}, 1 \mathrm{H}, \mathrm{Ar}-\mathrm{H})$, 7.83-7.95 (m, 3H, Ar-H), 8.01-8.10 (m, 2H, Ar-H), 8.16-8.25 (m, 3H, Ar-H), 8.42 (d, J 8.0 Hz, 1H, Ar-H), 8.61 (d, J 2.5 Hz, 1H, Ar-H), 8.90 (d, J 8.0 Hz, 1H, Ar-H) 10.25 (br, 1H, NH), 11.30 (br, 1H, NH), $11.38(\mathrm{t}, J 5.3 \mathrm{~Hz}, 1 \mathrm{H}, \mathrm{NH}) ;{ }^{13} \mathrm{C}$ NMR (50 MHz, DMSO-d $) \delta 39.7\left(\mathrm{CH}_{2}\right), 48.1$ $\left(\mathrm{CH}_{2}\right), 118.9(\mathrm{C}), 121.7(\mathrm{CH}), 124.1(\mathrm{CH}), 127.1(\mathrm{C}), 127.5(\mathrm{C}), 127.6(\mathrm{CH}), 127.9(\mathrm{CH}), 128.1$ $(\mathrm{CH}), 128.6(\mathrm{CH}), 128.8(\mathrm{CH}), 131.2(\mathrm{CH}), 131.7(\mathrm{CH}), 132.4(\mathrm{C}), 133.7(\mathrm{CH}), 135.6(\mathrm{C}), 138.5$ (C), $140.2(\mathrm{C}), 142.1(\mathrm{CH}), 143.5(\mathrm{C}), 150.7(\mathrm{CH}), 161.2(\mathrm{C})$. Anal. Calcd for $\mathrm{C}_{23} \mathrm{H}_{19} \mathrm{BrN}_{6} \mathrm{~S}: \mathrm{C}$, 56.22; H, 3.90; N, 17.10. Found: C, 56.38; H, 4.07; N, 16.88 .

1-(5-Bromopyridin-2-yl)-3-[2-(6-imino-3-methoxyisoindolo[2,1-a]quinoxalin-5(6H)-yl)ethyl] thiourea (4b). The residue eluted with DCM/Ethyl acetate 9/1. White solid; yield: 67\%; mp 243 ${ }^{\circ} \mathrm{C}$; IR $\left(\mathrm{CHBr}_{3}\right)$ v $3680(\mathrm{NH}), 3558(\mathrm{NH}), 1696(\mathrm{C}=\mathrm{NH}), 1297(\mathrm{C}=\mathrm{S}) \mathrm{cm}^{-1} ;{ }^{1} \mathrm{H}$ NMR $(200 \mathrm{MHz}$, DMSO-d $\left.d_{6}\right) \delta 3.95\left(\mathrm{~s}, 3 \mathrm{H}, \mathrm{OCH}_{3}\right), 4.16-4.24\left(\mathrm{~m}, 2 \mathrm{H}, \mathrm{CH}_{2}\right), 4.90\left(\mathrm{t}, J 5.1 \mathrm{~Hz}, 2 \mathrm{H}, \mathrm{CH}_{2}\right), 6.77$ (d, $J$ $8.6 \mathrm{~Hz}, 1 \mathrm{H}, \mathrm{Ar}-\mathrm{H}), 7.15$ (d, J $2.7 \mathrm{~Hz}, 1 \mathrm{H}, \mathrm{Ar}-\mathrm{H}), 7.35$ (dd, J 2.7, 8.6 Hz, 1H, Ar-H), 7.67-7.74 (m, 2H, Ar-H), 7.84 (t, J 7.4 Hz, 1H, Ar-H), 7.95-8.10 (m, 3H, Ar-H), 8.35 (d, J 7.4 Hz, 1H, Ar-H), 8.83 (d, J 7.4 Hz, 1H, Ar-H), 10.44 (br, 1H, NH), 11.22 (t, J 5.4 Hz, 1H, NH), 11.28 (br, $1 \mathrm{H}, \mathrm{NH}) ;{ }^{13} \mathrm{C}$ NMR $\left(50 \mathrm{MHz}, \mathrm{DMSO}-d_{6}\right) \delta 39.7\left(\mathrm{CH}_{2}\right), 43.0\left(\mathrm{CH}_{2}\right), 55.8\left(\mathrm{CH}_{3}\right), 105.2(\mathrm{CH})$, $111.5(\mathrm{C}), 113.8(\mathrm{CH}), 121.3(\mathrm{CH}), 123.5(\mathrm{CH}), 126.8(\mathrm{C}), 127.8(\mathrm{CH}), 127.9(\mathrm{CH}), 129.6(\mathrm{CH})$, $130.7(\mathrm{CH}), 132.5(\mathrm{C}), 132.7(\mathrm{C}), 133.3(\mathrm{CH}), 134.2(\mathrm{C}), 140.7(\mathrm{CH}), 141.9(\mathrm{C}), 144.1(\mathrm{C})$, 145.2 (CH), $151.7(\mathrm{C}), 161.1(\mathrm{C}), 161.4(\mathrm{C})$. Anal. Calcd for $\mathrm{C}_{24} \mathrm{H}_{21} \mathrm{BrN}_{6} \mathrm{OS}: \mathrm{C}, 55.28 ; \mathrm{H}, 4.06$; N, 16.12. Found: C, 55.53; H, 3.85; N, 16.42 .

\section{1-(5-Bromopyridin-2-yl)-3-[2-(2,3-dichloro-6-iminoisoindolo[2,1-a]quinoxalin-5(6H)-}

yl)ethyl] thiourea (4c). The residue eluted with DCM. Pale yellow solid; yield: 78\%; mp 228 ${ }^{\circ} \mathrm{C}$; IR $\left(\mathrm{CHBr}_{3}\right)$ v $3576(\mathrm{NH}), 3394(\mathrm{NH}), 1669(\mathrm{C}=\mathrm{NH}), 1297(\mathrm{C}=\mathrm{S}) \mathrm{cm}^{-1}$; ${ }^{1} \mathrm{H}$ NMR $(200 \mathrm{MHz}$, DMSO-d $d_{6} \delta$ 4.15-4.20 (m, 2H, $\left.\mathrm{CH}_{2}\right), 4.87\left(\mathrm{t}, J 5.6 \mathrm{~Hz}, 2 \mathrm{H}, \mathrm{CH}_{2}\right), 6.77$ (d, J 8.4 Hz, 1H, Ar-H), 
7.67-7.75 (m, 2H, 2 x Ar-H), 7.84 (s, 1H, Ar-H), 7.85-8.08 (m, 3H, Ar-H), 8.35-8.39 (m, 2H, ArH), 8.83 (d, J 7.0 Hz, 1H, Ar-H), 10.27 (br, 1H, NH), 10.43 (br, 1H, NH), 11.18 (t, J 5.6 Hz, 1H, $\mathrm{NH}) ;{ }^{13} \mathrm{C}$ NMR (50 MHz, DMSO- $\left.d_{6}\right) \delta 40.1\left(\mathrm{CH}_{2}\right), 42.9\left(\mathrm{CH}_{2}\right), 111.7(\mathrm{C}), 113.8(\mathrm{CH}), 116.4$ $(\mathrm{CH}), 117.1(\mathrm{C}), 118.3(\mathrm{C}), 124.2(\mathrm{CH}), 127.7(\mathrm{CH}), 127.8(\mathrm{CH}), 128.0(\mathrm{C}), 129.1(\mathrm{CH}), 130.6$ (C), $132.0(\mathrm{CH}), 133.2(\mathrm{C}), 133.6(\mathrm{CH}), 136.9(\mathrm{C}), 138.8(\mathrm{C}), 140.7(\mathrm{CH}), 145.1(\mathrm{CH}), 147.6$ (C), 151.1 (C), 161.5 (C). Anal. Calcd for $\mathrm{C}_{23} \mathrm{H}_{17} \mathrm{BrCl}_{2} \mathrm{~N}_{6} \mathrm{~S}$ : C, 49.30; H, 3.06; N, 15.00. Found: C, 49.17; H, 3.34; N, 15.32 .

1-(5-Bromopyridin-2-yl)-3-[2-(6-imino-2-methylisoindolo[2,1-a]quinoxalin-5(6H)-yl)ethyl]

thiourea (4d). The residue eluted with DCM. Pale yellow solid; yield: $81 \%$; mp $241{ }^{\circ} \mathrm{C}$; IR $\left(\mathrm{CHBr}_{3}\right) \vee 3570(\mathrm{NH}), 3384(\mathrm{NH}), 1674(\mathrm{C}=\mathrm{NH}), 1343(\mathrm{C}=\mathrm{S}) \mathrm{cm}^{-1} ;{ }^{1} \mathrm{H}$ NMR $\left(200 \mathrm{MHz}, \mathrm{CDCl}_{3}\right)$

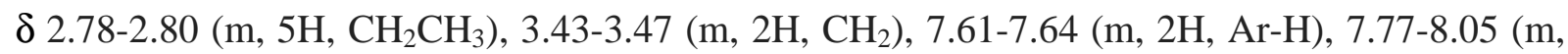
6H, Ar-H), 8.42-8.54 (m, 3H, Ar-H), 9.01 (t, J 5.0 Hz, 1H, NH), 9.22 (br, 1H, NH), 9.27 (br, 1H, $\mathrm{NH}) ;{ }^{13} \mathrm{C}$ NMR $\left(50 \mathrm{MHz}, \mathrm{CDCl}_{3}\right) \delta 17.3\left(\mathrm{CH}_{3}\right), 24.8\left(\mathrm{CH}_{2}\right), 29.7\left(\mathrm{CH}_{2}\right), 77.2(\mathrm{CH}), 108.3(\mathrm{C})$, $115.4(\mathrm{C}), 120.1(\mathrm{CH}), 124.8(\mathrm{CH}), 127.3(\mathrm{CH}), 128.0(\mathrm{CH}), 128.3(\mathrm{CH}), 130.9(\mathrm{CH}), 131.2$ $(\mathrm{CH}), 133.6(\mathrm{CH}), 133.9(\mathrm{C}), 134.7(\mathrm{CH}), 135.9(\mathrm{C}), 140.5(\mathrm{C}), 140.9(\mathrm{CH}), 141.9(\mathrm{C}), 149.4$ (C), 154.8 (C), 162.1 (C), 165.1 (C). Anal. Calcd for $\mathrm{C}_{24} \mathrm{H}_{21} \mathrm{BrN}_{6} \mathrm{~S}: \mathrm{C}, 57.03$; H, 4.19; N, 16.63 . Found: C, 56.83; H, 4.43; N, 16.91 .

\section{References}

1. De Clercq, E. Curr. Med. Chem. 2001, 13, 1543-1572. http://dx.doi.org/10.2174/0929867013371842

2. Tarby, C. M. Curr. Top. Med. Chem. 2004, 4, 1045-1057. http://dx.doi.org/10.2174/1568026043388295

3. Moyle, G. Drugs 2001, 61, 19-26. http://dx.doi.org/10.2165/00003495-200161010-00003

4. Huang, H.; Chopra, R.; Verdine, G. L.; Harrison, S. C. Science 1998, 282, 1669-1677. http://dx.doi.org/10.1126/science.282.5394.1669

5. Esnouf, R.; Ren, J.; Ross, C.; Jones, Y.; Stammers, D.; Stuart, D. Nat. Struct. Biol. 1995, 2, 303-308. http://dx.doi.org/10.1038/nsb0495-303

6. Das, K.; Lewi, P. J.; Hughes, S. H.; Arnold, E. Prog. Biophys. Mol. Biol. 2005, 88, 209-231. http://dx.doi.org/10.1016/j.pbiomolbio.2004.07.001

7. Sarafianos, S. G.; Das, K.; Hughes, S. H.; Arnold, E. Curr. Opin. Struct. Biol. 2004, 14, 716730.

http://dx.doi.org/10.1016/j.sbi.2004.10.013

8. Menendez-Arias, L. Antiviral Res. 2010, 85, 210-231. http://dx.doi.org/10.1016/j.antiviral.2009.07.006

9. Zhan, P.; Liu, X.; Li, Z. Curr. Med. Chem. 2009, 16, 2876-2889. http://dx.doi.org/10.2174/092986709788803231 
10. Song, Y.; Fang, Z.; Liu, X. Curr. Med. Chem. 2014, 21, 329-355.

http://dx.doi.org/10.2174/09298673113206660298

11. Patidar, A. K.; Jeyakandan M.; Mobiya A. K.; Selvam, G. Int. J. Pharmtech Research 2011, 3, 386-392.

12. Kleim, J. P.; Bender, R.; Billhardt, U. M.; Meichsner, C.; Riess, G.; Rosner, M.; Winkler, I.; Paessens, A. Antimicrob. Agents Chemother. 1993, 37, 1659-1664. http://dx.doi.org/10.1128/AAC.37.8.1659

13. Kleim, J. P.; Winters, M.; Dunkler, A.; Suarez, J-R.; Riess, G.; Winkler, I.; Balzarini, J.; Oette, D.; Merigan, T. C and the HBY 097/2001 Study Group. J. Infec. Dis. 1999, 179, 709713. http://dx.doi.org/10.1086/314633

14. Ren, J.; Nichols, C. E.; Chamberlain, P. P.; Weaver, K. L.; Short, S. A.; Chan, J. H.; Kleim, J-P.; Stammers, D. K. J. Med. Chem. 2007, 50, 2301-2309. http://dx.doi.org/10.1021/jm061117m

15. Xu, B.; Sun, Y.; Guo, Y.; Cao, Y.; Yu, T. Bioorg. Med. Chem. 2009, 17, 2767-2774. http://dx.doi.org/10.1016/j.bmc.2009.02.039

16. Campiani, G.; Aiello, F.; Fabbrini, M.; Morelli, E.; Ramunno, A.; Armaroli, S.; Nacci, V.; Garofalo, A.; Greco, G.; Novellino, E.; Maga, G.; Spadari, S.; Bergamini, A.; Ventura, L.; Bongiovanni, B.; Capozzi, M.; Bolacchi, F.; Marini, S.; Coletta, M.; Guiso, G.; Caccia, S. J. Med. Chem. 2001, 44, 305-315. http://dx.doi.org/10.1021/jm0010365

17. Barraja, P.; Diana, P.; Lauria, A.; Montalbano, A.; Almerico, A. M.; Dattolo, G.; Cirrincione, G.; Viola, G.; Dall'Acqua, F. Bioorg. Med. Chem. Lett. 2003, 13, 2809-2811. http://dx.doi.org/10.1016/S0960-894X(03)00529-8

18. Barraja, P.; Caracausi, L.; Diana, P.; Carbone, A.; Montalbano, A.; Cirrincione, G.; Brun, P.; Palù, G.; Castagliuolo, I.; Dall'Acqua, F.; Vedaldi, D.; Salvador A. Bioorg. Med. Chem. 2010, 18, 4830-4843. http://dx.doi.org/10.1016/j.bmc.2010.04.080

19. Barraja, P.; Caracausi, L.; Diana, P.; Montalbano, A.; Carbone, A.; Salvador, A.; Brun, P.; Castagliuolo, I.; Tisi, S.; Dall'Acqua, F.; Vedaldi, D.; Cirrincione, G. Chem. Med. Chem. 2011, 6, 1238-1248. http://dx.doi.org/10.1002/cmdc.201100085

20. Barraja, P.; Diana, P.; Spanò, V.; Montalbano, A.; Carbone, A.; Parrino, B.; Cirrincione G. Tetrahedron 2012, 68, 5087-5094. http://dx.doi.org/10.1016/j.tet.2012.04.041

21. Carbone, A.; Parrino, B.; Barraja, P.; Spanò, V.; Cirrincione, G.; Diana, P.; Maier, A.; Kelter, G.; Fiebig H-H. Marine Drugs 2013, 11, 643-654. http://dx.doi.org/10.3390/md11030643

22. Barraja, P.; Spanò, V.; Diana, P.; Carbone, A.; Cirrincione, G. Tetrahedron Lett. 2009, 50, 5389-5391. http://dx.doi.org/10.1016/j.tetlet.2009.07.045 
23. Barraja, P.; Diana, P.; Montalbano, A.; Carbone, A.; Viola, G.; Basso, G.; Salvador, A.; Vedaldi, D.; Dall'Acqua, F.; Cirrincione, G. Bioorg. Med. Chem. 2011, 19, 2326-2341. http://dx.doi.org/10.1016/j.bmc.2011.02.023

24. Spanò, V.; Montalbano, A.; Carbone, A.; Parrino, B.; Diana, P.; Cirrincione, G.; Castagliuolo, I.; Brun, P.; Issinger, O-G.; Tisi, S.; Primac, I.; Vedaldi, D.; Salvador, A.; Barraja, P. Eur. J. Med. Chem. 2014, 74, 340-357. http://dx.doi.org/10.1016/j.ejmech.2013.10.014

25. Barraja, P.; Diana, P.; Carbone, A.; Cirrincione G. Tetrahedron 2008, 64, 11625-11631. http://dx.doi.org/10.1016/j.tet.2008.10.022

26. Lauria, A.; Patella, C.; Diana, P.; Barraja, P.; Montalbano, A.; Cirrincione, G.; Dattolo, G.; Almerico, A. M. Heterocycles 2003, 60, 2669-2675. http://dx.doi.org/10.3987/COM-03-9877

27. Diana, P.; Stagno, A.; Barraja, P.; Carbone, A.; Parrino, B.; Dall'Acqua, F.; Vedaldi, D.; Salvador, A.; Brun, P.; Castagliuolo, I.; Issinger, O. G.; Cirrincione, G Chem. Med. Chem. 2011, 6, 1291-1299. http://dx.doi.org/10.1002/cmdc.201100027

28. Barraja, P.; Caracausi, L.; Diana, P.; Spanò, V., Montalbano, A.; Carbone, A.; Parrino, B.; Cirrincione, G. Chem. Med. Chem. 2012, 7, 1901-1904. http://dx.doi.org/10.1002/cmdc.201200296

29. Diana, P.; Carbone, A.; Barraja, P.; Montalbano, A.; Martorana, A.; Dattolo, G.; Gia, O.; Dalla Via, L.; Cirrincione, G. Bioorg. Med. Chem. Lett. 2007, 17, 2342-2346. http://dx.doi.org/10.1016/j.bmcl.2007.01.065

30. Diana, P.; Carbone, A.; Barraja, P.; Martorana, A.; Gia, O.; Dalla Via, L.; Cirrincione, G. Bioorg. Med. Chem. Lett. 2007, 17, 6134-6137. http://dx.doi.org/10.1016/j.bmcl.2007.09.042

31. Diana, P., Carbone, A.; Barraja, P.; Kelter, G.; Fiebig, H.-H.; Cirrincione, G. Bioorg. Med. Chem. 2010, 18, 4524-4529. http://dx.doi.org/10.1016/j.bmc.2010.04.061

32. Diana, P.; Carbone, A.; Barraja, P.; Montalbano, A.; Parrino, B.; Lopergolo, A.; Pennati, M.; Zaffaroni, N; Cirrincione, G. Chem. Med. Chem. 2011, 6, 1300-1309. http://dx.doi.org/10.1002/cmdc.201100078

33. Carbone, A.; Pennati, M.; Parrino, B.; Lopergolo, A.; Barraja, P.; Montalbano, A.; Spanò, V.; Sbarra, S.; Doldi, V.; De Cesare, M.; Cirrincione, G.; Diana, P.; Zaffaroni, N. J. Med. Chem. 2013, 56, 7060-7072. http://dx.doi.org/10.1021/jm400842x

34. Carbone, A.; Pennati, M.; Barraja, P.; Montalbano, A.; Parrino, B.; Spanò, V.; Lopergolo, A.; Sbarra, S.; Doldi, V.; Zaffaroni, N.; Cirrincione, G.; Diana, P. Curr. Med. Chem. 2014, 21, 1654-1666. http://dx.doi.org/10.2174/09298673113206660307

35. Barraja, P.; Spanò, V.; Diana, P.; Carbone, A.; Cirrincione, G.; Vedaldi, D.; Salvador A.; Viola, G.; Dall'Acqua F. Bioorg. Med. Chem. Lett. 2009, 19, 1711-1714. http://dx.doi.org/10.1016/j.bmcl.2009.01.096 
36. Diana, P.; Martorana, A.; Barraja, P.; Lauria, A.; Montalbano, A.; Almerico, A. M.; Dattolo, G.; Cirrincione, G. Bioorg. Med. Chem. 2007, 15, 343-349. http://dx.doi.org/10.1016/j.bmc.2006.09.054

37. Diana, P.; Martorana, A.; Barraja, P.; Montalbano, A.; Dattolo, G.; Cirrincione, G.; Dall'Acqua, F.; Salvador, A.; Vedaldo, D.; Basso, G.; Viola, G. J. Med. Chem. 2008, 51, 2387-2399. http://dx.doi.org/10.1021/jm070834t

38. Cirrincione, G.; Diana, P.; Parrino, B.; Carbone, A. Italian Patent RM2013A000588.

39. Barraja, P.; Spanò, V.; Giallombardo, D.; Diana, P.; Montalbano, A.; Carbone, A.; Parrino, B. Cirrincione, G. Tetrahedron 2013, 69, 6474-6477. http://dx.doi.org/10.1016/j.tet.2013.05.083

40. MacLeod, F.; Lang, S.; Murphy, J. A. Synlett 2010, 529-534.

41. Song, Y.; Zhu, B.; Bhakta, C.; Scarborough, R.M. PTC Int. Appl. 063293, 2006; Chem. Abstr. 2003, 139, 240348. 